\title{
The Mystery of Frightening Transcendent Experiences: A Rejoinder to Nancy Evans Bush and Christopher Bache
}

\author{
Mishka Jambor, M.A. \\ Sydney University, Sydney, Australia
}

\begin{abstract}
In this essay, I review Christopher Bache's (1994) perinatal account of near-death experiences (NDEs) and suggest that it does not go far enough. I then present a new model, bliss/abyss, derived from the study of mysticism; show that pleasant and frightening NDEs can be accommodated within the model; and discuss the predictions that can be drawn from the new theoretical framework. The implication for near-death research is that there may be several types of frightening NDEs beyond the three types recently identified by Bruce Greyson and Nancy Evans Bush (1992). I emphasize understanding the powerful emotional force that ensures that all frightening experiences, whether NDEs, perinatal, or spontaneous, have a taste of hell. Extending Bush's intuition, I argue that both pleasant and frightening transcendent experiences intimate the ultimate reality through the colored glasses of bliss and horror respectively. Finally, I suggest areas for further research.
\end{abstract}

I congratulate Nancy Evans Bush (1994) for doing justice to the frightening near-death experience (NDE) as "the depths of spiritual experience" as compared with the "heights" of the radiant NDE, and Christopher Bache (1994), for rehabilitating those who had or will have frightening NDEs.

Kenneth Ring (1994a, 1994b) and Bache noted some striking parallels between NDEs and mystical experiences. Bache concluded that "nearly dying is but a trigger that catapults persons with some con-

Mishka Jambor, M.A., is a Polish philosopher who researches human access to transcendence. Reprints of this article are not available, but Ms. Jambor can be reached at 306/99 Lilyfield Road, Lilyfield, New South Wales, Australia 2040. 
sistency into higher states of consciousness that can also be cultivated through various consciousness-expanding techniques" (1994, p. 38). Let us explore then transcendent experiences, whether obtained spontaneously, in meditation, in nearly dying, or triggered by psychedelic drugs. I include frightening as well as pleasant experiences in the category "transcendent." Both types, frightening and pleasant, transcend the ordinary waking state of consciousness in the direction of something experientially more real. My own account of frightening transcendent experiences will follow from a metaphysical scenario of the Beyond and bliss-horror duality, to be presented in the middle part of this essay. Let us explore first the usefulness of Bache's perinatal account.

\section{The Perinatal Account of NDEs}

Bache presented a detailed study of parallels between NDEs and perinatal experiences obtained under the influence of psychedelic drugs and during certain types of meditation. Given the close similarities between the three groups, one can inquire about them collectively. Where do all of these experiences come from? Carl Jung, for example, had an answer in terms of the collective unconscious and archetypes. What is their ontological status? Bache's is a phenomenological and classificatory work, as is Stanislav Grof's (1975), and as such does not venture into the exploration of origins and ontology. When it is claimed that NDEs have their patterning from birth, one needs to ask what aspects of the biological birth process enter into the structure of NDEs and what elements, if any, are of a transcendent character. Clearly, the sense of moving through a tunnel could have been structured by a memory of the birth process. However, peace, joy, and bliss, or horror and pain are less likely to be the fabrication of the biological birth process, while the pure transcendent experiences occurring in some NDEs, like that of John Wren-Lewis (1995), are clearly of such sublime character that to explain them through a biological process would constitute a case of medical reductionism. While such reductionism is a defensible position, Bache, like Ring and Bush, presented an alternative account whereby the transcendent aspects of perinatal experiences and of NDEs are given their due. Bache agreed with Grof that "we must interpret the states of consciousness triggered by LSD [and by neardeath events] in terms of the psyche's inherent process, not in terms 
of biological responses devoid of psychological significance" $(1994, \mathrm{p}$. 31 ). But then, calling those states of consciousness "perinatal" privileges the biological and provides for misunderstanding.

Here is my own analysis of the perinatal account. There are two distinct yet intertwined aspects of perinatal experiences: the event stream, developing and changing over time; and the "fuel" or "coloring" of these experiences by frightening or pleasant emotions. Bache, like Grof, focused largely on the event feature and explained it in terms of a confluence of personal and transpersonal themes; one could then proceed to Jung or to Rupert Sheldrake (1981) for an explanation of how these motifs originate or perpetuate themselves. This explanation of sensory and cognitive content seems for Bache to constitute also the etiology of the emotional component. Yet this move is mistaken. No pattern from the "event stream" is inextricably linked with a given emotional tone; for example, sometimes tragic events are experienced in a serene way. More specifically, the power and viciousness of a frightening emotion at the perinatal level is too prominent to be subsumed under the sensory and cognitive categories.

I suspect that even the experiencers themselves would agree with this point, as it seems that the "what" of their experiences is less important to them than the "how"; for example, peaceful, calm, heavenly, and joyous, or horrifying, unbearable, merciless, agonizing, and frantic. All of the above words, which were extracted from NDE reports, and sometimes longer descriptions, point to some majestic and powerful emotions, which are at the core of most perinatal reports and of perhaps all NDEs. This mysterious, grand emotional force, sometimes pleasant in its various hues and sometimes frightening, calls for an exploration in its own right.

\section{The Abyss}

How can we approach the "other," the fluid, overwhelming emotional force, with conceptual tools more suited to the realm of discrete solid entities? What kind of beings are we, that we can feel in such a profound way that the feeling alone makes for heaven and hell (for otherwise the experience would only be judged cognitively as unusual and interesting)? Let us call the feeling of transcendent perinatal and mystical experiences "deep-feeling." What is its origin? If the pleasant deep-feeling could theoretically be assigned to Ring's "ulti- 
mate reality," to which I shall return later, we are left with the mystery of the frightening deep-feeling.

The frightening deep-feeling truly deserves the name "abyss." This abyss, with its viciousness and forcefulness, evokes all the relevant theories, concepts, and mythologies in order to explain it, but to no avail. Is that not trying to explain a higher-order phenomenon by a lower-order one? The recent all-is-good philosophies do not offer an adequate answer either. Does the "illusory separative ego fighting a phantom battle" (Ring, 1994a, p. 22) produce the powerful awareness-in-horror-and-agony, or is it the other way around: the sheer impact of that horror setting in motion all the defenses of an ego in order to avoid that striking reality?

It is possible, even likely, that our theoretical problem with frightening NDEs lies not in the "mixed levels of discourse: a tumbling of metaphysics and testable hypotheses, spiritual and psychological language" (Bush, 1994, p. 49), but in our metaphysics being partially wrong or incomplete.

Let us envisage the horror and extreme despair of an immobilized mother made to witness the screaming of her tortured daughter (Amnesty International, 1985). In that instance, would talk about an "illusory separative ego fighting a phantom battle" not only be inadequate to the situation but also constitute dishonor and mockery of agonies that we were lucky to the spared? Can our metaphysics and spiritual theory disregard the history of humankind "in which torture, abuse, starvation and humiliation occur a thousand times every day" (Farley, 1991, p. 214)? That such events prove so tragic depends on human vulnerability: the capacity for extreme suffering. As we know, however, these historical events are not the only horrors that befall humanity; many perinatal and transcendent experiences evoke the same or even greater intensity of suffering. The same force seems to encroach on us in psychosis and depression. We need to raise the question again, with a greater sense of urgency: what is that force, an abyss, into which mundane and transcendent events plunge us? The perinatal model does not explain this force, while accounting for the patterns within the event-stream.

Theories drawn from the study of mysticism are most likely to be of use, as NDEs and some perinatal experiences have much in common with traditional mystical experiences (Grey, 1985; Happold, 1963). My own theoretical framework, presented below, belongs to this category. I will first sketch a hierarchy of transcendent experi- 
ences and then draw implications for a novel understanding of the frightening force I call "abyss."

\section{The Beyond, and Bliss/Abyss Duality}

The reality accessed by radiant NDEs, as well as by inverted and hellish NDEs, is clearly not the ultimate state beyond space and time, beyond distinctions, and beyond form, since the standard radiant NDE has (1) a temporal quality, in which events develop in sequence, although the proceeding of time may differ from the everyday passage of time; (2) discrete events; and (3) spatial characteristics. Spiritual traditions as well as accounts of mystics have left us with intimations of the true Beyond, or at least of the realm beyond the sensory, imaginary, and conceptual.

The modern American mystic Franklin Merrell-Wolff wrote of this realm that

[t]he pure Nirvanic State of Consciousness is a Void, a Darkness and a Silence, from the standpoint of relative or subject-object consciousness. But taken on its own level it is an extremely rich state of consciousness that is anything but empty. (1973, p. 200)

For thought, and also for sense, It is truly Nothing. But to say, therefore, that it is nothing in every sense whatsoever is to imply that all being is necessarily a being for sense of thought. (1973, p. 240)

Merrell-Wolff's portrayal is quite characteristic of mystics' insistence that the realm Beyond is indeed beyond the sensory and the conceptual. What has not yet been spelled out is the emotional coloring of the Beyond. It is nowadays commonly assumed that the ultimate itself is of the nature of bliss. It is unlikely, however, that the Source, or ultimate reality, would be constituted by an elementbliss-that has an opposite-horror/pain. It is advisable to assume, after some mystics, that the Beyond is also beyond any pair of opposites, hence beyond bliss and horror. Merrell-Wolff supported such a point, as I shall show below. Hence the realm of pure bliss and abyss would be located somewhere "further down" in the hierarchy of being, not in the heart of the Beyond, although the Beyond must contain the possibility, or the "seed," of these separate states of bliss and horror. Here we approach the slippery slopes of metaphysical speculations, and we must be careful, as in speculation it is easy to slip unaware from one's path. Our resources for the following include 
mystical accounts, theological models, transpersonal research, intuition, and a sense of humility.

The Beyond is largely beyond our comprehension: possibly even mystics glimpse only a small slice of it, though to them it may seem to be All. We are concerned here in locating the profound duality so manifest in our world, the duality of the sensed good and evil. There have been suggestions that the subject-object dualism is the first breaking up of the nonduality of the Beyond. Here I put forward an alternative or complementary hypothesis: that awareness-in-bliss and awareness-in horror are the primordial building blocks of the manifest world; desire and aversion, enjoyment and pain, and even attraction and repulsion devoid of consciousness are the ground rules of the world of individuation. Perhaps time originates in that splitting as well. Lack of consciousness appears to be the effect of shutting up from awareness-in-horror, or abyss. Sensory impressions in lower biological forms constitute probably the initial emergence of individualized awareness, capable of fending off abyss. The sensory level would act as a defense, simultaneously recreating something of the beauty of the Beyond.

The emotional level of a conscious being would partially reveal and partake of the qualities of bliss and horror/pain, though the powerful intensity of the two forces would remain dimmed due to the additional entanglement of consciousness in sensory and later sensory/conceptual data. The deep-feeling of horror/pain that people sometimes experience would then be a prepersonal, prehuman primordial force. Rather than being a creation of biological evolution and of childhood trauma on the individual level, this force of abyss would turn out to be itself one of the engines behind evolution.

Another evolutionary step is the emergence of the cognitive: the mythological mind, the belief structure and the discursive thought, embedded in visualization and/or language. The cognitive functions largely as a shield against feeling, yet partaking sometimes of a deeper knowing. In this scenario the cognitive structure is also responsible for structuring the two deep-feelings into specific emotions, such as sadness, grief, or satisfaction.

In overview, the constituents of conscious individualized life seem to exhibit a dual function: a defense against abyss and a translation or refraction of the riches of the Beyond. Taking this duality as a major clue, we have created a version of a Chain of Being, comparable and complementary to the Great Chain of Being of the perennial philosophy (Wilber, 1984). My bliss/abyss model, diagrammed in 
Figure 1, posits two primordial forces of bliss and horror/pain as underground engines of human and other beings' behavior and experience. Ultimate reality, or the Beyond, would be on a still higher level, and devoid of any emotional coloring.

This metaphysical schema would require an extensive research to establish it as an adequate theory. As a hypothesis, it seems adequate enough. Let us just note two more points. First, the Biblical myth of Adam and Eve's forbidden knowledge of good and evil fits perfectly well into our scenario. The fall, a primordial discrimination of good and evil, achieved experientially in the split into bliss- and horrorconsciousness, constitutes the beginning of the process of individuation. It is a fall from divinity, and simultaneously a fall, or "involution" (Aurobindo, 1986) into worldliness. Second, human capacity to become supremely happy, without an external reason, and the capacity to suffer greatly, incommensurate to the initial stimulus or reason, seem to reflect that primordial split of undifferentiated consciousness, the Beyond.

Given our model of the Chain of Being as indicated by corresponding states of consciousness, we can now locate the frightening and

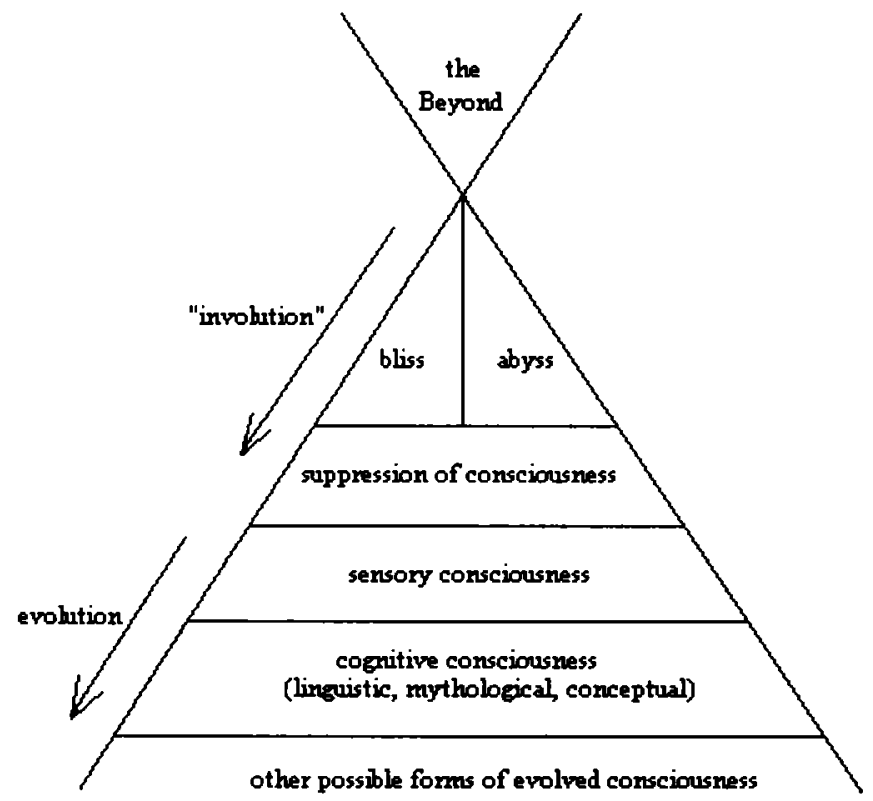

Figure 1. The bliss/abyss model. 
pleasant NDEs within this model, as well as predict new types of experiences.

\section{Frightening Transcendent Experiences: in the Grip of Abyss?}

Hellish, inverted, and pleasant NDEs belong to a class of experiences with supersensory components. They do not reach to the height of the Beyond. Nevertheless, they are a step or two toward it; they are glimpses of the Ultimate Reality, but spread over the sensory and supersensory content and colored frighteningly or pleasantly. However, some pleasant or frightening transcendent experiences would have surpassed the sensory and supersensory, but would remain structured by a cognitive component. The meaningless void is an example of this, as the experiential negating of the human-created meaning is of the cognitive order. Another example of this type of experience is the painful/lonely void, constructed by a cognitive element: the concept of loneliness, of not having suitable partners to relate to.

There may be several types of pleasant and frightening altered states of consciousness, all devoid of the sensory component, or where the sensory is experienced as irrelevant. Although near-death researchers have so far distinguished only one type of frightening nonsensory experience-the meaningless void-there is theoretical room for more varieties. Furthermore, Wren-Lewis's (1994) pleasant NDE did not fit the classical pattern, as it included no tunnel, no encounters with other beings, and so on. His was definitely a nonsensory NDE, and it is hard to judge on the basis of his written report alone whether or not this NDE was skewed by a structuring of some conceptual component.

There may be some NDEs that reach to those heights where cognitive and emotional structuring and coloring no longer occur; in this case they would parallel mystics' highest realizations. Returning to frightening NDEs, if the bliss/abyss schema is roughly correct we would expect some frightening transcendent experiences to be nonsensory and free of cognitive conceptual content, consisting solely of an unobstructed explosion of deep-feeling of horror/pain, the abyss. One would expect such an experience to be relatively rare; a counterpart absorption into bliss (nirvikalpa samadhi) is also quite rare, despite aspirants' prolonged efforts to reach it. Moreover, with the 
frightening experience, its awfulness would act as an inhibitor against disclosing it.

Are there any recorded experiences of pure abyss? I can suggest several possible candidates. One is what U.G. Krishnamurti, an Indian iconoclast who disposed of such cherished notions of humanity as mind, enlightenment, and love, referred to as a "calamity." This event, which happened to him some 30 years ago and of which he has no direct memory, became manifest through powerful aftereffects of physiological, sensory, and cognitive variety (Bhatt, 1992). On the whole, the event deprived him of all, or nearly all, defenses. This negativity, assessed as such by Krishnamurti himself, seemed to result in a free but unsatisfactory state of his mind.

Another possible candidate for the experience of abyss is what Emil Cioran, the Romanian-born philosopher, alluded to when he wrote: "The truth of one's being is a torture beyond what is bearable. He who does not lie before himself (if there is someone like this) is truly worthy of pity" (1976, p. 107, my translation). I presume he was alluding to a certain transcendent experience or experiences, rather than to an ordinary, day-to-day apprehension of the self. Moreover, he made a universal claim, and it is particularly transcendent or transpersonal experiences that lend themselves well to universalization. "The torture of experiencing one's own being" must be the most succinct description of the abyss experience.

The general problem with reports of the abyss seems to be the following: at present, no worldview, cultural or religious, allows for the possibility of a pure abyss experience, beyond the sensory or conceptual structuring; in consequence, those who would experience it to any extent are likely to explain it by transplanting the experience to existing thought systems or mythologies, hence overlaying it with extraneous elements.

It is this phenomenon, in my view, that we find in Simone Weil's writing on affliction. The experiential and religious dimension of suffering, and particularly affliction, figures largely in her work. She interprets more than describes, using her own original Gnostic-Christian framework. Between the lines, however, one can catch a glimpse of a peculiar inner experience, the inside of an affliction. The general condition of affliction concerns us here because it seems to constitute an ideal vehicle toward a pure abyss experience. In Weil's understanding, affliction involves three components creating a cumulative effect, a tragic one. The afflicted person undergoes a certain nonpsychotic breakdown, and experiences physical pain and pain of social 
ostracism. The breakdown consists of a progressive loss of a sense of one's self. What remains and grows is a dumb pain and despair; the Biblical Job seems an exemplar of this type of suffering. Consider the following descriptions:

Affliction is something which imposes itself on a man quite against his will. Its essence, the thing it is defined by, is the horror, the revulsion of the whole being which it inspires in its victim. (Weil, 1974, pp. 96-97)

In the case of someone in affliction, all the scorn, affliction, and hatred are turned inward. They penetrate the center of the soul and from there color the whole universe with their poisoned light. (Weil, 1951, p.122)

Here is my own interpretation of the dynamic of affliction as presented by Weil. From the bliss/abyss schema one would predict that the immersion in affliction, the increasing emotional pain, progressively eliminates the sensory and the cognitive as effective defenses. Hence the individual would be exposed more and more to unobstructed horror/pain.

From her own theological framework Weil advised sufferers to accept their affliction and even love it. Without going into the theological reasons behind her advice, we need to notice the outcome of following this advice from our perspective. To surrender to that horror/pain would mean to enter it fully. If the bliss/abyss model is correct, the sufferer would go through the abyss and either emerge into the Beyond, or experience suddenly the total relief from pain and experience themselves in the state of well-being, joyous, secure, totally purified, that is, under the influence of the deep-feeling of bliss. In fact, one illustration of some such process is a breakthrough of an Australian doctor, Iain Edwards, who unexpectedly emerged from utter despair upon losing his wife who had been brutally murdered. $\mathrm{He}$ "emerged" into a sense of well-being, calm, and serenity within minutes of the decision not to fight the overwhelming frightening feeling, a moment of surrender (Edwards, 1994).

The significance of pure abyss experience would require a separate study, gathering more empirical data and refining the theoretical framework. One can, however, show tentatively the relevance of abyss to the understanding of frightening NDEs. The abyss would be the source of the emotional tone of all frightening NDEs as well as being the limit of possible frightening experiences, whether mundane or transcendent: as they become more and more subtle, that 
is, as they lose their sensory and conceptual structuring, they would approach pure abyss.

We may also note at this stage that the bliss/abyss model points to a metaphysics more sensitive to the dual nature of human experience: there are experiences that feel good and those that are tainted with pain. Any metaphysics must pass the test of life. As Bush put it: "If the riddle of frightening experiences is to be found authentically, it must be in the fullness of nature, human and otherwise" (1994, p. 51).

\section{Real Joy and Unreal Pain?}

Ring (1994a), drawing on ideas from A Course in Miracles (1975), viewed frightening NDEs as illusory in some sense, in contradistinction to radiant NDEs; and while he later acknowledged the existential significance of the frightening ones, he did not retract his view of their ontological status (Ring, 1994b). From the perspective developed in this essay, the ambivalence of the status of frightening transcendent experiences can be fully accounted for as follows.

First, from the standpoint of the ultimate reality, all other levels of the Chain of Being, structured or colored by sensory, conceptual, emotional, and possibly other elements, are "illusory," or more accurately, less real, because supervening upon the basic "stuff," the ultimate. Second, from the standpoint of ordinary waking consciousness, both pleasant and frightening transcendent experiences, including NDEs, are more real, hence providing glimpses of the Beyond.

Against Ring's position, if fear be illusory or less real, so to must be joy and heavenly visions. But that is so only from the stance of the ultimate. Let us transpose this discussion to the realm of the mystical once more. Merrell-Wolff put forward this relevant argument against the valuing of the blissful state over pain:

But where there is valuation there is still duality-a difference between that which is valued and that which is depreciated. . . But it is not enough to arrive at the Place beyond evil; it is also necessary to transcend the Good. $(1976$, p. 246)

There is a sense in which we may speak of a bondage to Bliss as well as a bondage to pain. (1976, p. 244, emphasis added) 
In fact, Merrell-Wolff went so far as to deny the finality of the blissful Self that Shankara extolled, as Ring (1994b) noted. MerrellWolff distinguished between a "nirvanic" blissful state, precisely the Atman Brahman of Advaita Vedanta, as an intense subjective state disconnected from worldly content; and the all-encompassing yet alltranscending state, beyond the subjective and "objective" or worldly states. To realign the above categorization with the bliss/abyss model, an additional subjective state would have to be postulated: abyss, devoid of sensory, supersensory, and conceptual structuring. The distinction of the nirvanic state and the Beyond is, according to Merrell-Wolff, "extremely subtle, and yet of vital significance" (1976, p. 235).

Would the Beyond not include both bliss and horror/pain, being distinct from either? Perhaps many New Age philosophies mistake a partial realization of a blissful state for the final goal. If the distinction between the blissful and the ultimate seems not well grounded yet, possible evidence from other mystics or writers could be researched. Let us note, for example, that the famous 20th century Indian sage, Sri Aurobindo, has repeatedly argued the point that Shankara's solitary blissful Self is not the ultimate state (Aurobindo, 1986). Furthermore, he stated that

[e]ven the highest individual perfection, even the blissful cosmic condition is no better than a supreme ignorance. All that is individual, all that is cosmic has to be austerely renounced by the seeker of the Absolute Truth. (1986, p. 273)

So far near-death research has labored under the schism between the metaphysical and existential aspect of NDEs. This need not be so. We require a metaphysics that delivers straightforwardly the existential advice of taking both radiant and frightening NDEs equally seriously. Certainly the scenario of the Beyond and bliss/abyss duality goes part of the way toward such a metaphysics.

\section{Suggestions for Further Theoretical Research}

We need a series of questions to inspire a new theory, or a refinement of ones already in existence. First, as Bache (1994, p. 34) asked: "When so many people are frightened of death and ego dissolution, why are so few of them propelled into frightening NDEs?" 
Second, why is there such a "narrow thematic content" of frightening NDEs? Bache's answer-that perinatal experiences, including frightening NDEs, activate a level of the psyche where universal motifs prevail-seems quite satisfactory, but perhaps there are alternative explanations.

Third, is ego-death enough to transcend horror and pain? Or does ego-death make more room for both pleasant and frightening transcendent realities to be fully encountered? In other words, is identification with a specific psychophysical being the last block to be overcome? Is it a block at all?

Fourth, if Merrell-Wolff is right in viewing the transcendence of valuation as the sublime task beyond the immersion in bliss, how could it be carried out or lived?

Fifth, what is the essence of spiritual surrender? Has it got anything to do with facing abyss?

Sixth, is the traditional Christian and Buddhist view of pain as purification valid? What is being purified? Is purification another name for detachment from sensory and conceptual components of one's life, such as beliefs and worldview?

And finally, at what point are we filled with true love and compassion? Could near-death research contribute to the longstanding philosophical enquiry into the nature of good and evil?

\section{References}

Amnesty International. (1985). Women and torture [File on torture, 2]. London, England: Amnesty International.

Aurobindo, S. (1986). The synthesis of yoga. Pondicherry, India: Sri Aurobindo Ashram.

Bache, C. (1994). A perinatal interpretation of frightening near-death experiences. Journal of Near-Death Studies, 13, 25-45.

Bhatt, M. (1992). U. G. Krishnamurti: A life. New York, NY: Viking.

Bush, N. E. (1994). The paradox of Jonah: Response to "Solving the riddle of frightening near-death experiences." Journal of Near-Death Studies, 13, 47-54.

Cioran, E. M. (1993). Aforyzmy. Warsaw, Poland: Czytelnik.

Course in miracles, A. (1975). Tiburon, CA: Foundation for Inner Peace.

Edwards, I. (1994, February). The day love died. ITA Magazine [Sydney, Australia], pp. 20-24.

Farley, W. (1985). Ethics and reality. Philosophy Today, 36, 210-220.

Grey, M. (1985). Return from death: An exploration of the near-death experience. London, England: Arkana.

Greyson, B., and Bush, N. E. (1992). Distressing near-death experiences. Psychiatry, 55, 95-110.

Grof, S. (1975). Realms of the human unconscious. New York, NY: Dutton.

Happold, F. C. (1963). Mysticism: A study and an anthology. Baltimore, MD: Penguin. 
Merrell-Wolff, F. (1973). The philosophy of consciousness without an object: Reflections on the nature of transcendental consciousness. New York, NY: Julian Press.

Ring, K (1994a). Solving the riddle of frightening near-death experiences: Some testable hypotheses and a perspective based on $A$ course in miracles. Journal of NearDeath Studies, 13, 5-23.

Ring, K. (1994b). Frightening near-death experiences revisited: A commentary on responses to my paper by Christopher Bache and Nancy Bush. Journal of Near-Death Studies, 13, 55-64.

Sheldrake, R. (1981). A new science of life: The hypothesis of formative causation. Los Angeles, CA: Tarcher.

Weil, S. (1951). Waiting for God (E. Craufurd, Trans.). New York, NY: Putnam.

Weil, S. (1974). Gateway to God (D. Raper, Trans.). London, England: Collins.

Wilber, K. (1984). Quantum questions. Boulder, CO: Shambhala.

Wren-Lewis, J. (1994). Aftereffects of near-death experiences: A survival mechanism hypothesis. Journal of Transpersonal Psychology, 26, 107-115. 